\title{
CAUTIVERIOS CONTEMPORÁNEOS DE PRIMO LEVI A SU SOMBRA EN ESPAÑA: MONTSERRAT ROIG Y JORGE SEMPRÚN
}

\author{
FAnNy Rubio \\ Universidad Complutense de Madrid \\ frubio@filol.ucm.es
}

Homenaje a Florencio Sevilla

«Viendo un dolor sobrehumano» (Miguel de Cervantes, Los baños de Argel).

«Recuerdo haber vivido ese año en Auschwitz en un estado de ardor excepcional: debía a mi formación profesional, a una resistencia insospechada o bien a un instinto profundo. Nunca dejaba de observar el mundo y a la gente a mi alrededor, hasta tal punto que aún hoy sigo conservando una visión muy precisa de todo aquello. Experimentaba el deseo intenso de comprender. Constantemente era presa de una curiosidad que, más adelante, alguien calificó de hecho, nada menos que de cínica». Phillip Roth, «Primo Levi. Entrevista» $(1986,2017)$. «Nada jamás desviará el curso de este sueño, el flujo de esta Laguna Estigia» (Jorge Semprún).

$\mathrm{M}$

llama poderosamente la atención que en la entrevista de Phillip Roth a Primo Levi citada más arriba se destaque el concepto de «curiosidad», curiosidad, en su caso, por lo que era capaz de hacer el hombre en el estadio de ignominia de los campos de concentración nazis; curiosidad irrenunciable que actúa como motor de la experiencia extrema en el periodo de la vida de Levi transcurrido en Auschwitz. Una curiosidad equivalente al concepto de «silencio», más potente que «resiliencia», del grupo de mujeres de Ravensbrück investigadas por Montserrat Roig; curiosidad que gesta en un segundo estadio su equivalente «fraternidad», el irrompible vínculo que extrae Jorge Semprún de las admirables sombras de potencia misteriosa descubiertas en el campo de Buchenwald. A Semprún le llamará también la atención el término «curiosidad» de Primo Levi y lo destacará como un sentimiento compartido cada vez que tenga oportunidad de comentar la obra del escritor italiano. 


\section{ENTRE ESTO Y AQUELLO}

Primo Levi (1919-1987) fue capturado el 13 de diciembre de 1943, a la edad de 24 años, por su condición de judío y resistente. Ese día concreto forma parte del memorial del autor, como cuentan uno a uno las víctimas del holocausto «el día» de sus detenciones. Tanto los relatos de Levi a partir de Si esto es un hombre, como las crónicas de los presos y presas de Ravensbrück tratados por Montserrat Roig en Noche y niebla: Los catalanes en los campos nazis, y las escenas relatadas por Jorge Semprún en La escritura o la vida (1995) y Viviré con su nombre, morirá con el mio (2001), nacen siempre de una fecha y un lugar en la historia vivida que acompaña a los protagonistas a lo largo de toda su existencia. Ligados a la curiosidad están «los otros», no aparte, «ligados» a la viva imagen del narrador que comparte en el escarnio con sus personajes el tiempo y el espacio. Con ellos el narrador sitúa su lugar de memoria compasiva en momentos excepcionales hasta ese instante no narrado, desconocido, para el lector común. A lo largo del proceso de escritura, la mirada se escapa del sujeto para vivir en la piel de los otros, siempre, digo, de manera excepcional, dada la lucha por la vida de todos. En los tres narradores, la escena inicial parte de unos ojos extrañamente sobrecogidos en la noche o en el amanecer en familia, atropellados por una detención y un itinerario a través del espanto. En la obra de los tres autores se describe, más o menos morosamente, el trayecto compartido con la masa humana, en los trenes con destino desconocido, y la llegada del gigantesco grupo humano en situación de necesidad a los barracones de un campo de ignominia igualmente atestados de seres humanos que se reemplazan en tandas de exterminio, sujetos de la durísima experiencia forzada en el campo de trabajo, el centro de las jornadas evocadas a lo largo de sus atormentados recuerdos vitales. En ese espacio de extrañamiento, sin precedentes en la memoria de los protagonistas, cobran forma rostros humanos con los que se han compartido los enigmas en un lugar concreto del mapa de Europa: Francia, Alemania, Polonia...

La obra de Primo Levi describe in situ la extenuante jornada laboral: el esfuerzo penoso de trasladar pesados tubos de hierro, piedras colosales, vigas para construir de un sitio a otro, trabajo intenso y permanente en los talleres de fabricación de calderas o piezas aéreas de las que depende el final de la guerra. Son presos vestidos con harapos, que asfaltan y construyen piezas de guerra defensivas con la sola ayuda de sus brazos, mientras sortean bajas temperaturas de frío polar. Justamente, la nieve es la expresión térmica de los relatos que evocan el paisaje temible durante el periodo transcurrido. La nieve, nueva fórmula de enorme poder evocador que romperá con su caída suave los procesos ulteriores del olvido. El frío acompaña la crónica de Primo Levi, cuando aborda como si fuese una investigación científica, la conducta del arsenal humano que recuerda. También sucede en las páginas memorialísticas de Jorge Semprún, que comienzan con el bagage 
cultural de quien formara parte de una familia ligada al poder político y a la intelligentsia de la República española, atado fatalmente a aquel desconocido infierno de terror. En ellos, la desventura se transmuta en conocimiento compartido y, a veces, sorprendentemente empático, por lo que lo sórdido se metaboliza por acto de escritura en lazo nuevo. Del barracón de Primo Levi al trabajo en la oficina de los traslados, donde se halla Semprún y al taller de las mujeres de Ravensbrück, con agravante de género, como es el sometimiento de muchas de ellas a los experimentos médicos, la realidad escondida y contada, pese a lo que pese, se abre paso implacable por primera vez en la historia ante los ojos del lector.

Hay que reconocer que las obras de los tres autores vivieron cierto éxito, un éxito que no fue ajeno a la crítica por parte de sectores relacionados con las historias relatadas que a posteriori aportaron datos nuevos. Los tres estuvieron distanciados entre sí por distintos motivos entregados al relato de su experiencia. Prueba de ello es que, en plena Transición española, Roig solicitó una entrevista a Semprún, y este no consideró oportuno aceptarla, de la misma manera que Semprún en su día se negó a conocer a Primo Levi, por más que una amiga común se lo propusiera. Pasado el tiempo, tras la muerte de Montserrat Roig, Jorge Semprún se aproximó a la novela del narrador italiano y dedica unas páginas a la lectura de su obra. De haber vivido Roig, seguramente ella y Semprún se habrían encontrado por puro interés común, mediando José María Castellet, buen amigo y editor de ambos.

Las extenuantes jornadas en el campo de reclusión, que se relatan de la mano de la obra de los tres autores, dan cuenta de aquella multitud de seres blindados por su tragedia, «como atrezzo» fatal en la crónica. En Si esto es un hombre, Primo Levi considera la necesidad que tiene la población confinada de referirse, cuando están juntos, lejos del vigilante, a lo elemental del universo del sobreviviente:

Hemos aprendido el valor de los alimentos; ahora también nosotros raspamos diligentemente el fondo de la escudilla después del rancho y nos la ponemos bajo el mentón cuando comemos pan para no desperdiciar las migas. También sabemos ahora que no es lo mismo recibir un cucharón de sopa de la superficie que del fondo del caldero y ya estamos en condiciones de calcular, basándonos en la capacidad de los distintos calderos, cuál es el sitio más conveniente al que aspirar cuando hay que hacer cola (1976: 34$)$.

Con esa precariedad, Primo Levi reconstruye el espacio, capaz de notificar en sus páginas la caducidad de la existencia. En ocasiones se alude al compañero de confinamiento en función de su nacionalidad («los judíos griegos», los «prominentes judíos», los «ingenieros», los «yidish», los «húngaros») y con la misma naturalidad se asume fatalmente la convivencia de vivos con cuerpos murientes y con muertos. Con precisión rescatadora el narrador anota los rasgos de los tipos 
que lo rodean, sus medidas, sus silencios, sus fuerzas, incluso sus consejos pícaros, como el del personaje que pontifica con humor: «Para sobrevivir hace falta organización, compasión y hurto» (1976: 108). La voz narrativa se alimenta de los vocablos y el argot del campo; pero Levi calcula como físico el paso inexorable del tiempo, tanto la llegada de la primavera como del frío polar que se anuncia en los meses previos. Y, como biólogo, anticipa la duración aproximada de una vida teniendo en cuenta el ritmo agotador de los recluidos durante el transcurso de los primeros tres meses de padecimiento, aunque lo más sencillo — concluye Levihubiera sido sucumbir. Primo Levi se detiene en la apertura de la agonía de sus iguales narrada hasta que llega la distensión de lo imprevisto a la espera de ese segundo mágico, en que los confinados celebran encontrarse bajo un sol de justicia. En él, el luchador antifascista y judío teje visionario el futuro de la liberación: «Aquí y hoy - escribe Primo Levi- nuestra finalidad es llegar a la primavera» (1976: 77). La anterior visión de la nieve es sustituida por el símbolo de la regeneración. Por eso, en el «Apéndice» incluido en la edición de 1976 de Si esto es un hombre, escribe haber mantenido

la voluntad, que conservé tenazmente, de reconocer siempre, aún en los días más negros, tanto en mis camaradas como en mí mismo, a hombres y no a cosas, sustrayéndome de esta manera a aquella total humillación y desmoralización que condujo a muchos al naufragio espiritual (1976: 222).

La voz del narrador se erige en el papel de sobreviviente y de testigo, no juez, de lo vivido. Es su manera de alertar acerca del tiempo futuro y de los nuevos fascismos transmutados. Tanto en el prólogo a un volumen preparado en Italia con la memoria de doscientos testigos supervivientes de los campos nazis, como en su libro de ensayos Los hundidos y los salvados deja constancia de una verdad asumida.

Para nosotros, hablar con los jóvenes es cada vez más difícil. Lo sentimos como un deber y a la vez como un riesgo: el riesgo de resultar anacrónicos, de no ser escuchados. Tenemos que ser escuchados: por encima de toda nuestra experiencia individual hemos sido colectivamente testigos de un acontecimiento fundamental e inesperado, fundamental precisamente porque ha sido inesperado, no previsto por nadie. Ha ocurrido contra las previsiones; ha ocurrido en Europa [...]. Ha sucedido y, por consiguiente, puede volver a suceder: esto es la esencia de lo que tenemos que decir (1989: 88).

\section{MontserRat Roig y LaS SOBREVIVIEntes de RaVENSBRÜCK}

El lugar es, a vista de pájaro, un paisaje idílico. Himmler había mandado construir ese campo de tamaño pequeño, Ravensbrück, junto a la bella Villa de Furstenberg 
y un hermoso lago que hoy sirve de esparcimiento a acogedoras colonias escolares berlinesas de vacaciones. Héctor Barnés comenta, en su impactante artículo «Ravensbrück, el campo de concentración para mujeres del que nadie quería hablar» (2016), un libro de Sarah Helm y nombra a Anise Postel-Vinay, una de las últimas supervivientes de ese campo de confinamiento. Capturada en Le Havre, describe a «aquellas mujeres desfiguradas, grises, con la mirada ausente, nos asustamos. De repente sentimos que entrábamos en una zona de muerte» (2016). Ocuparon los barracones ocho mil francesas, mil holandesas, dieciocho mil rusas, cuarenta mil polacas y pocas inglesas. Muchas en silencio absoluto, como Yvonne Baseden, legendaria resistente de las Fuerzas Especiales de los aliados. El silencio como caja de resonancia del ser humano ante el mundo depredador. De entre ellas, más de un centenar de mujeres romaníes esterilizadas, miles de comunistas, centenares de intelectuales como la pintora Gerda Lissack o la musa de Kafka, Milena Jesenska, muerta a los 48 años de una insuficiencia renal en el campo de Ravensbrück. Compartían pequeños adornos que les recordaban sus lazos fraternales, pequeños símbolos de fraternidad. Aunque la consigna era no hablar de lo ocurrido para no inmortalizar a sus verdugos, durante décadas el recuerdo de Ravensbrück se partió en dos: el de las heroínas mitificadas en sus entornos políticos en los países de procedencia y el del silencio, el desconocimiento, la ignorancia de las sobrevivientes por parte de sus contemporáneos. De ahí, la importancia de Los catalanes en los campos nazis, crónica exhaustiva, informe minucioso de nombres propios, anotación notarial de terror en los campos bajo la óptica de los catalanes, con su edad, su lugar de procedencia, su pasado republicano o su actitud ante las SS. Con esta motivación la escritora Monserrat Roig (1946-1991) presentó, en 1979, en Madrid, su libro, del que conocemos distintas ediciones (1977, 2017). Roig ya era reconocida en lengua catalana por las novelas Tiempo de cerezas (1977) y La hora violeta (1978). También lo era como periodista, militante del PSUC y feminista. Si exceptuamos a Max Aub o Manuel Andújar, durante la Transición política española no se veía con gran interés publicar este tipo de informes. Por eso, escribir este libro y publicarlo posteriormente situó a la escritora como disidente a contrapelo de la cultura que iba a implantarse en nuestro país en unos años que ya se empezaba a apostar, salvo excepciones, por la cultura del entretenimiento que en poco tiempo iba a desembocar industrialmente en la famosa y todavía pendiente de ser interpretada a fondo, «movida».

Durante el tiempo en que Roig preparaba su libro, la sociedad que iba a remolque del avance político no echaba de menos el testimonio de los supervivientes del holocausto. Tampoco le ayudó que los documentos sobre el juicio de Ravensbrück permanecieran clasificados durante largos años hasta los años ochenta. Hoy conocemos algo más por la parte rusa, alemana o francesa, de los estragos y las vicisitudes padecidas por las presas de Ravensbrück y la condena desde 1946 con 
motivo de los juicios de Hamburgo a las guardias acusadas de crímenes contra la humanidad, aunque durante tiempo se asumió falsamente que Ravensbrück era considerado campo de trabajo y no de concentración.

Tal vez por ello, Montserrat Roig cita el «cerco de silencio» que rodea a los supervivientes: que, con los trajes de presos en fotografías difundidas treinta años más tarde «podían molestar» a los herederos del franquismo ya con barniz «democrático». Las supervivientes, bajo sospecha en una España en plena dictadura a partir de 1950, reciben nulo reconocimiento, y con dificultades añadidas. Roig denuncia, pese a hallarse en el edén teórico del postfranquismo, las dificultades que rodean la publicación de su libro, pero no se queda en la simple crítica: en una entrevista con la también escritora y periodista Rosa María Pereda, el jueves 15 de marzo de 1979, en el diario El País, Roig valora sus hallazgos:

Conocer a los sobrevivientes ha sido para mí una experiencia terrible. Ellos son la prueba del horror, y por eso resulta tan grotesca la polémica sobre si hubo o no cámaras de gas en determinados campos nazis en Francia, y tan espantosa la campaña de olvido de los crímenes del nazismo. He comprobado que los supervivientes de los campos sufren su experiencia hasta el punto de serles casi imposible hablar de ella; he visto hombres con sesenta años y curtidos llorar como críos, y conozco una mujer que me confesó revivir aquello en forma de pesadilla cada noche... El síndrome de los campos — la secuela psicológica — existe, como la última consecuencia del nazismo.

Cita Roig a ocho mil republicanos españoles muertos en campos de concentración nazis, seis mil en el de Mauthausen, y se arriesga a la proporcionalidad de dos sobrevivientes en un grupo de cuarenta y siete republicanos. Muchos de estos presos, republicanos detenidos en Francia y trasladados a distintos campos, eran etiquetados como «sin patria». El testimonio de Francesc Boix en el juicio de Nuremberg (14 de noviembre de 1946), las fotografías de Paul Ricken, y en particular el tesón de Neus Catalá, presidenta de Amical de Ravensbrück hasta su fallecimiento reciente a los 103 años, le allanan un camino poblado de dificultades.

Concretamente, —confiesa Roig — a los refugiados de Angulema se les negó la realidad de su nacionalidad española, y les colocaron el triángulo azul de los apátridas. Cuando hablé de este tema, que concernía a 6.000 muertos, dos tercios de los detenidos - los españoles morían en la misma proporción que los judíos, aunque su número era mucho más bajo-- Serrano Súñer, que era el responsable de las relaciones entre el Gobierno franquista y el Tercer Reich, no supo o no quiso contestar.

El campo se creó con apenas dos mil recluidas entre alemanas antinazis y quinientas testigos de Jehová. Después llegaron las republicanas españolas, o un 
menor número de prisioneras judías que empezaron a ser deportadas a Auschwitz, en el verano de 1942. A estos grupos se añadieron, durante la guerra, miembros de los equipos de operaciones especiales de los aliados, detenidos tras aterrizar en paracaídas sobre suelo alemán. También miembros de la resistencia francesa; su distintivo: un triángulo de color que identificaba su categoría y nacionalidad. Obligadas en su mayoría las checas y polacas a afeitar su cabeza y a trabajar en la fábrica de Siemens situada al lado del campo, colaboraban en construir y muchas veces sabotear los componentes de los cohetes V-2. A partir de agosto de 1941, empeoraron las condiciones de sobrevivencia y cada día fallecían unas ochenta internas por enfermedades relacionadas con el hambre, las infecciones, el maltrato, las carencias, el envenenamiento, el «gaseamiento», la ejecución y la muerte. Unas ciento treinta mil mujeres pasaron por el campo. Contrastando números y opiniones, dando dobles y triples versiones de cada uno de los casos en función de los contradictorios informantes, Roig realiza la primera radiografía, asombrada por el material hallado. Se detiene en las normas de marzo de 1941 que extiende la ley de la eutanasia a los enfermos que tardan en curarse más de tres meses; y la de mayo del 41, que califica a los detenidos de Dachau, «humanos para el estudio de la resistencia humana en los vuelos de gran altura», como conejillos de indias. Hoy son de sobra conocidas las prácticas con cuerpos humanos y otras atrocidades entre humanas y animales en el campo de Ravensbrück, donde se probaban medicamentos inyectados a las internas; uno de estos, cortar huesos, músculos y nervios de las mujeres e infectarlos con bacterias, a través de piezas de madera o cristal, para probar medicamentos; otro, trasplantar huesos de una mujer a otra, por lo que ambas quedaban mutiladas. Ya se conocen las cifras exactas, pero la obra de Roig es pionera en la recopilación de la memoria. Nos recuerda que en Ravensbrück llegaron a morir entre treinta mil y noventa mil mujeres, alojándose en su peor momento en estos habitáculos un número nada desdeñable de cuarenta y cinco mil cautivas hacinadas. En los días finales, los oficiales de las SS obligaron a veinticuatro mil sobrevivientes a caminar hacia Mecklenburg huyendo del Ejército Rojo, en una de las marchas de la muerte más terribles que se recuerda. Muchas de las que quedaron no tuvieron mejor suerte, ya que fueron violadas por los soldados rusos. En esa cima de horror los testimonios de las supervivientes se imponen: coinciden en señalar, como en el caso de lo analizado después por Jorge Semprún, que fue el compañerismo entre las víctimas lo que permitió que saliesen adelante, que resistieran la tortura, afrontaran la muerte con fuerza inusitada y dejaran su legado de irrompible lazo. La prueba la tenemos en la legendaria Neus Catalá, ejemplo de entrega a la causa y memoria de las mujeres que murieron en Rabensbrück, de donde ella logró salir viva y recientemente fallecida a los 103 años. La presidenta de la asociación Amical de Ravensbrück, Anna Sallés, resaltó en su entierro la entrega y lucha por la memoria de las mujeres en ese campo de 
exterminio en defensa de la democracia y la igualdad desde su militancia comunista y su trabajo constante en memoria de las luchadoras antifascistas.

\section{Jorge Semprún: entre el SUeÑo, LA VIDA y LA PIEL Del otro}

Cuatro años más joven que Primo Levi, y diecisiete años mayor que Montserrat Roig, Jorge Semprún (1923-2011) pertenece a la burguesía española republicana y con un abuelo que había presidido el Consejo de Ministros del Gobierno español en cinco ocasiones. Al finalizar la guerra española se refugia con su familia en Francia. Su padre había trabajado en La Haya como alto funcionario de la República, pero en 1939 los Semprún, como exiliados y con pocos medios, se refugian en Francia. Su militancia en la Resistencia en Francia, el partido comunista francés, primero, y el PC español se conoce sobradamente como dirigente clandestino del mismo partido comunista bajo el pseudónimo de Federico Sánchez, como relata en sus memorias, siendo expulsado de la misma organización por disidente en 1964. Su perfil político y su azarosa y cinematográfica vida de intelectual omnipresente en la vida europea desde que era adolescente hasta su muerte ha eclipsado la meditación obsesiva a la que somete su escritura. Entre 1988 y 1991, el Gobierno socialista lo nombrará Ministro de Cultura. Entre otras distinciones europeas fue investido como doctor honoris causa por la Universidad de Potsdam en la primavera de 2007. Se han sucedido numerosas publicaciones, artículos y libros escritos dentro y fuera de la familia del escritor, con afán reivindicativo o cariñosamente depredadores, de entre los que destaco la completa biografía de J.S. escrita por Soledad Fox Maura, que, aunque no evita bromas acerca de su pariente a la manera americana, relata sus idas y venidas de manera muy documentada, apoyándose en archivos y testimonios que enriquecen el perfil humano de Semprún en su impactante periplo familiar, político y mediático.

En Francia fue durante mucho tiempo el rouge espagnol, en España un rojo afrancesado. Para los franquistas fue un radical militante y para los comunistas nunca dejó de ser un aburguesado. Para los nazis era enemigo y prisionero de guerra, y para algunos su experiencia en Buchenwald no contaba tanto porque, como no era judío —únicamente prisionero de guerra - y hablaba alemán, le trataron mejor. ¿Cómo pudo vivir Semprún entre tantas sandeces, tanto odio, tanta envidia? (2011: s.p.)

Fuera de los años de infancia, contada y recontada hasta la saciedad por miradas propias y ajenas, no menos se ha citado su militancia en la resistencia francesa, la detención en 1943 y la deportación al campo de Buchenwald, del que fue liberado en 1945. Viviré con su nombre, morirá con el mío es su manera personal de «recrear» el acontecimiento: en el invierno de 1944, una escena aparece de manera 
reiterada en sus libros. La dirección central de los campos de concentración envía un requerimiento a la oficina de la Gestapo en Buchenwald acerca del deportado Jorge Semprún, de 20 años, matrícula 44904. Interceptado el mensaje, los comunistas que lo protegen planean sustituir al joven por un preso agonizante: « $i$ Ya tenemos el muerto que necesitábamos!» (2001: 15). Ese relato memorialista recreado por Semprún, junto a un par de anécdotas que van y vienen retornando a sus páginas, reaparece en la casi totalidad de su obra narrativa que explora tanto los paisajes del París ocupado como la lucha antifascista en la resistencia y la experiencia del campo de concentración. «Entre estas dos fechas, 1941 y 1943, había habido en mi vida un acontecimiento considerable: había descubierto las obras filosóficas de Karl Marx. Había sentido pasar sobre todas mis ideas, sobre mi manera de estar en el mundo, el soplo avasallador del Manifiesto del partido comunista, un verdadero huracán» (2001: 120). Y en Buchenwald entre los comunistas españoles madura la idea del papel que ha de cumplir años después a la clandestinidad como Federico Sánchez. Describe primero cómo los testigos de Jehová pasan en secreto la información a la organización clandestina y pronto el personaje entra en una relación de intercambio con un preso que agoniza y muere con el nombre de quien le va a sobrevivir. A partir de aquí, se suceden uno a uno distintos relatos, como el que asoma en un primer plano de esa figura épica que adelanta con su fuerza disponible el desarrollo de la contienda mundial y establece redes de solidaridad en medio de un tumulto de adolescentes rusos, judíos organizados y catedráticos agonizantes: un «tovarich» corpulento y simpático, exponente internacionalista, que alivia la cuesta en el traslado de una pesada piedra adjudicada por los negreros al joven burgués comprometido.

En la obra de Semprún la mirada del personaje se eleva con la humareda del crematorio que asciende fuera del control de los «kapos» con firmeza cinematográfica. Mas el universo compasivo no queda ahí: se manifiesta en los detalles más pequeños, mientras alguien rumia calculador una simple mata de manzanilla conformando el derecho a otro espacio, tal vez iluminado, en medio de la sordidez. Lo leemos primero en Primo Levi:

Hoy el sol ha surgido vivo y nítido fuera del horizonte de barro, es un sol polaco, frío, blanco y lejano, y no nos calienta más que la epidermis, pero cuando se ha deshecho de las últimas brumas ha corrido un murmullo por nuestra multitud $\sin$ color; incluso cuando incluso yo he sentido su tibieza a través de mi ropa, he comprendido que se pueda adorar al sol (1987: 77).

También, en Aquel domingo, Jorge Semprún comenta la referencia luminosa del primer astro al que interpela en su carencia: «Pero el sol acaba de desaparecer, allá, detrás de la línea de los montes de Turingia. La noche cae de repente, como una capa de plomo o de hielo» (1999: 445). Es un muchacho que traslada su vivencia cultural a los compañeros de cautividad: lee ¡Absalon! ¡Absalon! de William 
Faulkner, prepara un acto cultural con poemas de Lorca y se muestra aplicado recitador de Rimbaud, Baudelaire, César Vallejo y René Char («Liberté: derrière l'absence, elle est venue, cygne sur la blessure par cette ligne blanche»). Tanto en su obra Aquel domingo como en la ficción autobiográfica que sigue el narrador, Jorge Semprún regresa a esa figura del inconsciente atravesada por el tren de la historia, desde la infancia burguesa, la militancia juvenil en el marxismo y la frustración ideológica en los avatares del partido comunista español. En el centro de las evocaciones, la cima: el campo de Buchenwald bajo la colina de Ettersberg y el recuerdo de los dieciocho meses de cautiverio en la oficina, el «Arbeitsstatistik», por la ventaja de hablar alemán y sobrevivir gracias a triquiñuelas casuales. Con el tiempo reconoce que Buchenwald transforma su mente y su físico. La mirada en ese espejo y la escritura que lo nombra refleja los estragos del acontecimiento, el signo del horror de quienes miran, esos cincuenta mil detenidos de Buchenwald, testigos de la última batalla perdida de las SS. Contemplar el semblante de Léon Blum en su caída desde la cúspide de la política francesa a su deportación a la zona del campo reservada en aquel fatídico 1943 lo hace asimilar desde adentro las vueltas de su vida. Ver los rostros de un grupo de judíos polacos, abandonados bajo la lluvia, integra la pintura de la humanidad derrotada en la base de sus emociones. La cita de Alexander Solzhenitsyn de 1974 en el trigésimo aniversario de la liberación de Buchenwald, como muestra de solidaridad: «Tanto en los campos rusos como en los alemanes, los rusos se llevaron la peor parte» (encabezamiento de Aquel domingo). Ni los procesos de Praga, ni las pugnas con Santiago Carrillo de las que se libera en 1963 a partir de un viaje en tren blindado a través de Rumanía, leyendo las cartas de Franz Kafka a Milena que alimentan la libertad de su conciencia, le harán callar este romántico referente internacionalista. Antes había alimentado su moral recitando ante el camastro del moribundo profesor de La Sorbona, Halbwachs, junto a Henri Maspero, unos versos de Baudelaire, versos que escapan a las descripciones del momento, para forjar en su mente un símbolo irrompible. El símbolo sigue haciendo el lazo cuando, al ser excluido del PCE, Louis Aragon le lleva a su casa su novela La mise à mort con la dedicatoria: «Contra viento y marea».

En El largo viaje (1963), sigue la pesadilla camino del campo, destacando cómo las bocas llenan el espacio con diálogos camino del absurdo. De nuevo habla el Semprún de 1943, con las vivencias ahora amortiguadas por la edad del narrador, más despegado del personaje joven. Como un Semprún de 1995 en La escritura o la vida (1995), donde reencuentra a Primo Levi:

Leí La tregua de Primo Levi en 1963. No sabía nada de él hasta entonces. No había leído su primer libro, Se questo é un uomo. Bien es verdad que deliberadamente había evitado la lectura de los testimonios sobre los campos nazis. Formaba parte de una estrategia de supervivencia. [...] en otoño, el tiempo de la sordera para conmigo mismo también: para con la parte más oscura pero más verdadera de mí 
mismo [...] En cualquier sitio, en suma, con cualquiera, de golpe, una angustia difusa y profunda, la certidumbre angustiada del fin del mundo; de su irrealidad en cualquier caso. Primo Levi habla de ello en la última página de La tregua. Habla de ello sin levantar la voz, con concisión, con la sequedad de los enunciados de verdades (1995: 254-267).

Antes Semprún se había negado por ofrecimiento de la escritora Rosana Rossanda a conocer a Primo Levi. No le pareció ni necesario ni conveniente. Más adelante en La escritura o la vida leemos un epígrafe, «El día de la muerte de Primo Levi» (1995: 241), y recordará finalmente una de las frases del memorialista italiano: «Tutto è ora volto in caos», confirmando que «todo se vuelve caótico cuando esta angustia reaparece» (1995: 254).

En 1987, Primo Levi escogería la muerte en su casa de Turín, el 11 de abril de 1987. Ese 11 de abril, piensa Semprún, el día del aniversario de la liberación de Buchenwald, ese día, la muerte le había dado alcance. Más adelante, Semprún recordará la entrevista de Primo Levi con Phillipe Roth aludiendo a la «curiosidad» de la que hemos hablado y a una sencilla observación: «no hay una regla general, excepto la de llegar al campo en buen estado de salud y saber alemán» (1995: 319). En el momento de la muerte de Primo Levi, Jorge Semprún reconoce el impacto que produce en él la noticia escuchada en un informativo donde se habla de lo importante que es tener valor para afrontar la muerte. Y, a propósito de la edad del escritor italiano, Semprún comenta:

Pero yo no tenía necesidad de este valor... Iba a escribir para mí mismo, por supuesto, sólo para mí [...] Entonces, con un estremecimiento que me sacudió toda el alma, me dije que me quedaban todavía cinco años de vida. Primo Levi era, en efecto, cinco años mayor que yo (1995: 260-261).

Apenas se estremece con los rostros que vuelven a la historia en el momento de la liberación de Buchenwald por el ejército norteamericano y el general Patton. La escena que vive medio siglo después en el mismo paraje de su confinamiento es la de un sonámbulo. No es la épica la que lo reclama, era la vida: «Entonces fue cuando oí el murmullo múltiple de los cantos de los pájaros. Después de todo, habían acabado por volver al Ettersberg. El susurro de sus cantos me rodeaba como un rumor oceánico. La vida había vuelto a la colina del Ettersberg» (1995: 315). Y en el dilema entre testimonio y creación la pesadilla no opta por el testimonio, sino por la creación y la recreación de la experiencia vivida. En La escritura o la vida (1995), el recuerdo aparece convertido en azar de manera obsesiva, colocado frente a la herida fría que renueva la posibilidad de la escritura. Ya no es la visión del propio cuerpo en el campo mientras mira y es mirado en las condiciones de un deportado en la desgracia; ni atender del 
grupo de informantes a las noticias de Léon Blum mientras lo llevan al dentista. Es percibir el mismo olor ahora, en otra realidad. Escuchar la misma risa tras la expresión coloquial de «irse por la chimenea». El dato reiterado de los cincuenta mil detenidos en trance de ser rescatados y la llegada de los libertadores el 12 de abril de 1945 adquiere un poder actual, renace un «aparecido»: «esa muerte antigua recuperaba sus derechos imprescriptibles, invadiendo el más trivial de los presentes, en cualquier ocasión» (1995: 234).

Los itinerarios del pasado son simples paréntesis de olvido mientras llega el torrente perturbador de la memoria tras leves curas de desmemoria.

Y el emplazamiento de Weimar-Buchenwald podría convertirse en el lugar simbólico de memoria y de futuro. Pero la nieve había caído sobre mi sueño. Cubría el bosque nuevo que había crecido sobre el emplazamiento del Campo Pequeño. Sobre los miles de cadáveres anónimos, que no se habían desvanecido en humo, como sus hermanos de antaño, que se descomponían en la tierra de Turingia.

Caminaba por la nieve profunda, entre los árboles, con Thomas y Mathieu Landman. Les explicaba dónde se había ubicado el bloque 56. Les hablaba de Maurice Halbwachs. Les señalaba dónde había estado el edificio de las letrinas, les contaba nuestras sesiones de recitación de poemas, con Serge Miller e Yves Darriet.

De repente, ya no conseguían seguirme [...] yo tenía veinte años y caminaba muy deprisa entre los torbellinos de nieve, aquí mismo, pero muchos años antes. Me desperté en la habitación del hotel Elephant. Ya no estaba soñando, había regresado a ese sueño que había sido mi vida, que será mi vida (1995: 326-327).

El último Semprún es capaz de contemplar un árbol con la mirada de su propia muerte; admirar la belleza de la ciudad de Goethe, Weimar, y fundir el Madrid de la guerra civil con el París del Bois de Boulogne, en el paisaje de Buchenwald, donde el protagonista está recibiendo de un compañero tres cigarrillos y una contraseña. Es un narrador que trastoca los tiempos hacia adelante y hacia atrás con más exactitud que nunca, pasando de una novela a otra. Estamos en 1960, con Federico Sánchez en crisis visitando Berlín Oriental en compañía de un chófer local mientras se aloja en el Parkin, o quizás Unter den Linden. Recuerda al joven alemán de la Weshrmarcht cantando «la paloma» y en el campo a punto de ser liberado el gran cartel de Stalin en el barracón de los soviéticos, como si saltara una alerta en el momento justo, como el canto de la muerte de los judíos.

No estaba seguro de ser un sobreviviente de verdad. Había atravesado la muerte, esta había sido una experiencia de mi vida. De repente al contemplar a los deportados con traje de rayitas en la rue de Faubourg [...] no estaba del todo seguro de haber vuelto. Comprendí de dónde provenía la tristeza que me afligía, a pesar de la impresión engañosa de estar ahí vivo, en la Place de la Nation, aquel 1 de mayo. 
Y es que precisamente no estaba del todo seguro de estar ahí, de haber vuelto realmente (1995: 155-156).

¿Era el recurso a la poesía el que propicia la inversión de los tiempos y otras recurrencias ligadas al discurso metaliterario? ¿Fue el poema de César Vallejo, de Paul Celan, la trompeta de Louis Armstrong lo que propició el «retorno masivo de las antiguas angustias» en otro tiempo y desde otro espacio? Los retornos a Primo Levi, su vivo retrato en los tiempos postreros, han sido frecuentes.

En Milán, en la Via Bigli, en la Biblioteca de los Banfi, ahí leí «La tregua», de Primo Levi. [...] Había cerrado los ojos en la última página del libro. Me había acordado de Lorene, en Locarno, de mi decisión de abandonar el manuscrito en curso, en 1945. [...] Rossana Rossanda fue quien me facilitó para su lectura el relato de Levi, así como su primer libro, «Si esto es un hombre». Me propuso conocerle, ella podía organizar el encuentro. Pero yo no experimentaba la necesidad de conocer a Primo Levi. Quiero decir, de conocerlo «fuera», en la realidad exterior de ese sueño que, desde nuestro regreso, era la vida. Me parecía que entre nosotros ya estaba todo dicho. O que, desde entonces, era imposible de decir. No me parecía necesario, tal vez ni siquera conveniente, que tuviéramos una conversación, un diálogo de supervivientes [...] Además, ¿habíamos sobrevivido realmente? [...] El 11 de abril de 1987, en cualquier caso, aquel sábado durante el cual, a la vuelta de una frase, de improviso, el fantasma del joven deportado que yo había sido surgía en una novela donde no estaba previsto, ni se le esperaba, sembrando la confusión, echando una mirada llena de incertidumbre, Primo Levi escogía la muerte tirándose por el hueco de la escalera de su casa de Turín. [...] Entonces, con un estremecimiento que me sacudió toda el alma, me dije que me quedaban todavía cinco años de vida. Primo Levi era en efecto cinco años mayor que yo. [...] El pasado se hacía, pues presente. Volvía el aparecido. La escritura liberaba a Primo Levi del pasado, a mí me hundía otra vez en la muerte (1995: 264-265).

He aquí un «lapsus» de lucidez del meditador de Semprún que ya no es el personaje autobiográfico sino la voz que encarna la actividad de la memoria que no se acalla hasta ser plenamente nombrada. Cuando Primo Levi muere, Semprún se pregunta por qué Primo Levi había perdido «la paz que la escritura parecía haberle devuelto» (1995: 269). Ya estaba convencido del poder terapéutico de la literatura para hacer nacer vida desde la muerte padecida, creándola en otra dimensión que solo el escritor conoce, liberándose por eso mismo al mismo tiempo de ella. Se define como «sobreviviente de turno» puesto que «lo angustioso no era morir, era vivir» sin la conciencia nueva que le da el escribir en «una especie de resurrección» que lo ha convertido en «aparecido». Lo percibió al encontrarse con el camarada madrileño que ha salido de otro campo de concentración y es su anfitrión en su estancia clandestina en el Madrid de 1961. Era un «aparecido» tras la 
experiencia del mal. Semprún sabe que esa experiencia abandonada durante dieciséis años a partir de El largo viaje debía ser escrita, como se dice un sábado de marzo de 1992 en su visita conmemorativa en Buchenwald:

Nada en la novela que estaba escribiendo en abril de 1987 permitía prever una deriva hacia la sombra donde arraiga, haga lo que haga, al margen del ardid o de la razón que emplee para alejarme de él, un deseo de vivir. Y mi incapacidad permanente para conseguirlo plenamente (1995: 245).

El personaje Roger Marroux llega al territorio de la realidad el 12 de abril de 1945, pero estamos 42 años más tarde, en el 11 de abril de 1987. La antigua «esquizofrenia concertada» de ensoñaciones automáticas en las que transcurren los recuerdos de su infancia, etc., se transmuta experimentando una «desconcertante felicidad» al escribir ese pasado:

Rocé con la mano las letras de la inscripción labrada en el hierro forjado de la reja de entrada, JEDEM DAS SEINE (A CADA CUAL LO SUYO). Volvía a casa, quiero decir al mundo de mis veinte años... la belleza dramática que se abría ante mi vista (1995: 311). 


\section{BIBLIOGRAFÍA}

BARNÉs, Héctor (2016). «Ravensbrück, el campo de concentración para mujeres del que nadie quería hablar». El Confidencial, 27/11/2016.

Fox MAURA, Soledad (2011). «Jorge Semprún: extraño en todas partes». Revista de libros, 177 $<$ https://www.revistadelibros.com/articulo_imprimible.php?art=5007\&t=articulos $>$ [Consulta: 12/04/2021].

Fox Maura, Soledad (2016). Ida y vuelta. La vida de Jorge Semprún. Madrid: Debate / Penguin Random House.

Levi, Primo (1987). Si esto es un hombre. Pilar Gómez Bedate (trad.). Madrid: Austral.

Nieto, Felipe (2014). La aventura comunista de Jorge Semprún. Barcelona: Tusquets.

Mesa, Sara (2019). «Primo Levi y el sentido de la superviviencia». Letras Libres, 1 de julio. RoIG, Montserrat (2017 [1977]). Los catalanes en los campos nazis. Madrid: Península.

Roth, Philip (2017). «Entrevista a Primo Levi». ¿Por qué escribir? New York: The Library of America.

SEMPRÚn, Jorge (1963). El largo viaje. Barcelona: Tusquets.

SEMPRún, Jorge (1995). La escritura o la vida. Barcelona: Tusquets.

SEMPRún, Jorge (1999). Aquel domingo. Barcelona: Tusquets.

SEMPRÚN, Jorge (2001). Viviré con su nombre, morirá con el mío. Barcelona: Tusquets.

Recibido: 09/05/2021

Aceptado: 25/06/2021 


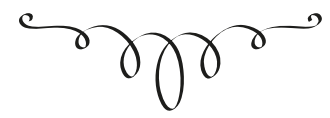

Cautiverios contemporáneos de Primo Levi a su sombra en España:

Montserrat Roig y Jorge Semprún

RESUMEN: Tanto los relatos de Levi a partir de Si esto es un hombre, relativos a su estancia en el campo de concentración nazi de Auschwitz como las crónicas de los presos y presas de Ravensbrück tratados por Montserrat Roig en Noche y niebla: Los catalanes en los campos nazis, y las escenas relatadas por Jorge Semprún en La escritura o la vida (1995) y Viviré con su nombre, morirá con el mío (2001), acerca de sus vivencias en el campo de concentración de Buchenwald, nacen siempre de una fecha y un lugar en la historia vivida que no se borrará nunca de la mente de los protagonistas. De manera enigmática, los tres relatos, aparentemente independientes y separados uno de los otros, se van a entrelazar.

Palabras Clave: Sobrevivientes, Ravensbrück, Buchenwald, sueño, vida.

\section{Contemporary captives of Primo Levi in its shadow in Spain: Montserrat Roig and Jorge Semprún}

ABSTRACT: Both Levi's stories from If This is a Man, relating to his stay in the Nazi concentration camp Auschwitz, as well as the chronicles of the prisoners of Ravensbrück treated by Montserrat Roig in Noche y niebla: Los catalanes en los campos nazis (Night and fog: The Catalans in the Nazi camps), and the scenes narrated by Jorge Semprún in Writing or life (1995) and Viviré con su nombre, morirá con el mío (I will live with his name, he will die with mine) (2001), about his experiences in the Buchenwald concentration camp, will never be erased from the minds of their protagonists. In an enigmatic way, the three stories, apparently independent and separated from one another, are going to intertwine.

Keywords: Survivors, Ravensbrück, Buchenwald, dream, life. 